\title{
Dampak Pemulihan Mangrove Terhadap Bahan Baku, Kesempatan Kerja dan Pendapatan Keluarga Pesisir
}

\author{
Julian Hisky Tyas Pambudi \\ Program Studi Agribisnis, Fakultas Pertanian, Unika Santo Thomas Medan \\ Email : tyaspambudi91@gmail.com
}

\begin{abstract}
This study which was conducted in the coastal area of Rugemuk Village, Pantai Labu Subdistrict, Deli Serdang Regency aims to 1) analyze the impact of mangrove forest recovery program on mangrove cover area; 2) analyze the impact of mangrove recovery program on availability of raw materials of coastal agroindustry; 3) analyze the impact of mangrove forest recovery program on employment opportunities; 4) analyze the impact of mangrove recovery program on coastal household income. Data analysis method used in this research is comparative method that is Wilcoxon Match Pairs Test and Test-t. Sampling method used is simple random sampling method with the number of samples of 79 samples. The results showed that 1) There is increasing mangrove forest cover area after mangrove restoration program; 2) There is significant difference availability of raw materials of coastal agroindustry; 3) There is significant difference employment opportunities before and after mangrove restoration program; 4) There is significant difference in coastal household income before and after mangrove restoration program.
\end{abstract}

Keywords: Impact of Mangrove Recovey, Cover Area, Availability of Agroindustry Raw Materials, Employment Opportunities, Household Income

\begin{abstract}
Abstrak
Penelitian yang dilaksanakan di kawasan pesisir Desa Rugemuk, Kecamatan Pantai Labu, Kabupaten Deli Serdang ini bertujuan untuk 1) menganalisis dampak program pemulihan hutan mangrove terhadap luas tutupan hutan mangrove; 2) menganalisis dampak program pemulihan hutan mangrove terhadap ketersediaan bahan baku agroindustri pesisir; 3) menganalisis dampak program pemulihan hutan mangrove terhadap kesempatan kerja; 4) menganalisis dampak program pemulihan hutan mangrove terhadap pendapatan rumah tangga pesisir. Metode analisis data yang digunakan dalam penelitian ini adalah metode komparatif yaitu Wilcoxon Match Pairs Test dan Uji-t. Metode pengambilan sampel yang digunakan adalah metode Simple Random Samplingdengan jumlah sampel 79 sampel. Hasil penelitian menunjukkan bahwa 1) Terjadi peningkatan luasan tutupan hutan mangrove setelah program restorasi hutan mangrove; 2) Terdapat perbedaan signifikan ketersediaan bahan baku agroindustri pesisir sebelum dan sesudah program restorasi mangrove; 3) Terdapat perbedaan signifikan kesempatan kerja sebelum dan sesudah program restorasi mangrove; 4) Terdapat perbedaan signifikan pendapatan rumah tangga pesisir sebelum dan sesudah program restorasi mangrove.
\end{abstract}

Kata Kunci: Dampak Pemulihan Mangrove, Luas Tutupan Mangrove, Ketersediaan Bahan Baku Agroindustri, Kesempatan Kerja, Pendapatan Keluarga Pesisir

\section{PENDAHULUAN}

Mangrove merupakan ekosistem yang sangat produktif. Keberadaannya mampu memperkaya keanekaragaman hayati, menghasilkan berbagai produk hutan komersial, melindungi garis pantai, serta mampu mendukung produksi perikanan di kawasan pesisir. Mangrove memiliki sistem adaptasi yang unik mengingat kondisi lingkungannnya yang ekstrim, seperti kadar garam yang tinggi serta tanah yang kurang stabil dan tergenang. Hamparan mangrove di Indonesia adalah yang terbesar di dunia, yaitu dengan luas $3.112 .989 \mathrm{~m}^{2}$ atau $22,6 \%$ dari luas mangrove yang ada di dunia. Namun dalam beberapa tahun terakhir, faktor antropogenik telah memberikan pengaruh pada ekosistem mangrove ini. Sekitar $45 \%$ mangrove di Indonesia telah mengalami degradasi cukup parah karena aktivitas manusia. Jumlah kerusakan tersebut diperkirakan akan semakin meningkat seiring dengan pertumbuhan dan perkembangan pemukiman di kawasan pesisir (Auliyani dkk., 2013).

Hutan mangrove memiliki nilai ekonomis dan ekologis yang tinggi, tetapi sangat rentan terhadap kerusakan apabila kurang bijaksana dalam mempertahankan, melestarikan dan pengelolaannya. Kondisi hutan mangrove pada umumnya memiliki tekanan berat sebagai akibat dari tekanan krisis mangrove yang berkepanjangan. Selain dirambah dan dialihfungsikan, pada kawasan mangrove di beberapa daerah kini marak dilakukan kegiatan restorasi dan rehabilitasi. Kegiatan tersebut dilakukan untuk memulihkan kondisi ekosistem mangrove yang telah rusak agar ekosistem mangrove dapat menjalankan kembali fungsinya dengan baik. Upaya rehabilitasi harus melibatkan seluruh lapisan masyarakat yang berhubungan dengan kawasan mangrove (Novianty dkk., 2004)

Desa Rugemuk sebenarnya memiliki 
aksesibilitas relatif tinggi dengan pusat-pusat pertumbuhan yang ada. Jarak tempuh Desa ke Kota Kecamatan sekitar 15 menit, Desa ke Kota Kabupaten 1 jam, jarak tempuh Desa ke Kota Provinsi 2,5 jam dan jarak tempuh ke Bandara International Kuala Namo sekitar 25 menit. Luas wilayah Desa Rugemuk pada tahun 2013 adalah sekitar 300 ha atau $3 \mathrm{~km}^{2}$ dengan perincian penggunaan lahan terdiri atas pemukiman penduduk 25 ha, persawahan 180 ha, rawa-rawa 9 ha, perkebunan 13 ha, pertambakan 25 ha, hutan mangrove sekitar 38 ha dan penggunaan lainnya 10 ha. Sebagian besar (sekitar 70\%) hutan mangrove yang ada di wilayah Desa Rugemuk selama beberapa tahun (tahun 2000 hingga tahun 2013) mengalami kerusakan parah dan terus terkonversi menjadi penggunaan lain seperti permukiman, perladangan, peternakan dan pertambakan. Dampak fisik rusaknya mangrove tersebut adalah terjadinya abrasi kuat pada seluruh pantai serta meningkatnya banjir pasang (rob) di kawasan tersebut. Kerusakan kawasan mangrove ini telah berdampak ke berbagai sektor kehidupan masyarakat Desa Rugemuk yang bermuara pada tingginya tingkat kemiskinan di desa tersebut. Pada tahun 2013 proporsi penduduk miskin Desa Rugemuk mencapai $40 \%$ dan merupakan yang tertinggi di antara desa-desa di wilayah Kabupaten Deli Serdang (BPS Kabupaten Deli Serdang, 2013).

Sejak tahun 2013 hingga tahun 2017, dengan inisiasi Lembaga Pengabdian pada Masyarakat Universitas Sumatera Utara (LPPM USU), telah dilakukan pemulihan kawasan mangrove melalui pendekatan partisipatif yang bersifat komprehensif yang mengkombinasikan pemulihan biofisik mangrove, pendekatan sosial kelembagaan dan pendekatan ekonomi melalui pengembangan agroindustri berbasis mangrove. Selama 4 tahun berturut-turut program tersebut dilaksanakan melalui kolaborasi antar lembaga yaitu Perguruan Tinggi, Pemerintah Daerah dan pihak Swasta. Program pemulihan mangrove tersebut diperkirakan telah berdampak terhadap sosial ekonomi masyarakat sekitarnya. Oleh karena itu, sehubungan dengan hal tersebut perlu dilakukan penelitian terkait dampak program rehabilitasi hutan mangrove terhadap kondisi sosial ekonomi masyarakat pesisir di Desa Rugemuk.

\section{TINJAUAN PUSTAKA \\ Dampak}

Pengertian dampak menurut Kamus Besar Bahasa Indonesia adalah pengaruh yang mendatangkan akibat baik positif maupun negatif. Pengaruh adalah daya yang ada dan timbul dari sesuatu (orang, benda) yang ikut membentuk watak, kepercayaan atau perbuatan seseorang. Pengaruh adalah suatu keadaan dimana ada hubungan timbal balik atau hubungan sebab akibat antara apa yang mempengaruhi dengan apa yang dipengaruhi
(KBBI Online, 2010).

\section{Restorasi Mangrove}

Restorasi mangrove merupakan upaya memulihkan kawasan hutan mangrove yang mengalami kerusakan (degraded) atau terganggu (disturbed) akibat aktivitas manusia atau gangguan alam. Dengan upaya restorasi, kemungkinan pulihnya proses ekologi akan kembali, serta dengan upaya ini, ketahanan yang menjadi syarat berlangsungnya pemulihan sistem dapat tercapai.

Program restorasi berupaya memulihkan kembali ekosistem sebagaimana mulanya. Oleh karena itu, mengetahui keadaan awal suatu ekosistem sangatlah diperlukan sebagai dasar perencanaan program restorasi. Dalam hal ini intervensi sosial sangat diperlukan sebagai upaya perubahan terencana ekosistem yang membutuhkan restorasi atau ekosistem yang telah mengalami perubahan atau kerusakan akibat aktivitas-aktivitas manusia. Intervensi sedemikian dapat dimulai dengan perubahan individu, kelompok, maupun komunitas (Septyohadi, 2004).

\section{Luas hutan mangrove}

Undang-undang No. 5 tahun 1990 tentang Konservasi Sumber Daya Alam Hayati dan Ekosistemnya merupakan suatu kekuatan dalam pelaksanaan konservasi kawasan hutan mangrove. Kawasan hutan mangrove ini, baik dari segi fisik dan biologi sangat berkaitan dengan penguatan ekonomi masyarakat pesisir. Di dalam undang-undang tersebut terdapat tiga aspek yang sangat penting, yakni sebagai berikut:

a) Perlindungan terhadap sistem penyangga kehidupan dengan menjamin terpeliharanya proses ekologi bagi kelangsungan hidup biota dan keberadaan ekosistemnya.

b) Pengawetan sumber plasma nutfah, yaitu menjamin terpeliharanya sumber genetik dan ekosistemnya, yang sesuai bagi kepentingan kehidupan umat manusia.

c) Pemanfaatan secara lestari atau berkelanjutan, baik berupa produksi dan jasa.

\section{Ketersediaan bahan baku agroindustri pesisir}

Definisi agroindustri dapat dijabarkan sebagai kegiatan industri yang memanfaatkan hasil pertanian sebagai bahan baku, merancang dan menyediakan peralatan serta jasa untuk kegiatan tersebut, dengan demikian agroindustri meliputi industri pengolahan hasil pertanian, industri yang menproduksi peralatan dan mesin pertanian, industri input pertanian (pupuk, pestisida, herbisida, dll) (Udayana, 2011).

Agroindustri dapat diartikan sebagai industri yang berbahan baku utama dari produk pertanian. Pengolahan bahan baku (raw material) pertanian ini merupakan aktivitas ekonomi yang meningkatkan nilai tambah. Dalam arti luas, agroindustri mencakup komoditas pertanian pangan dan komoditas 
pertanian non-pangan perkebunan, kehutanan, hortikultura dan kelautan dan komoditas pangan perkebunan, kehutanan, hortikultura dan kelautan (Ichsan, 2017).

Hutan mangrove yang terpelihara baik memiliki potensi biota tangkapan yang baik dan meningkatkan ketersediaan bahan baku agroindustri pesisir (Murdiyanto, 2003). Agroindustri yang berkembang di Desa Rugemuk adalah industri belacan dan udang kering dengan bahan baku utama adalah udang.

Hutan mangrove sangat menunjang perekonomian masyarakat pantai, karena merupakan sumber mata pencaharian masyarakat yang berprofesi sebagai nelayan. Secara ekologis hutan mangrove di samping sebagai habitat biota laut, juga merupakan tempat pemijahan bagi ikan yang hidup di laut bebas. Jenis biota tangkapan/bernilai ekonomis mangrove dan keunikannya juga memiliki potensi sebagai wahana hutan wisata dan atau penyangga perlindungan wilayah pesisir dan pantai, dari berbagai ancaman sedimentasi, abrasi, pencegahan intrusi air laut, serta sebagai sumber pakan habitat biota laut. Pulih kembalinya kawasan mangrove seperti sediakala sebelum terdegradasi, menjamin kembali pulihnya habitat bagi biota dan satwa liar (Waryono, 2013).

\section{Kesempatan bekerja/berusaha}

Kesempatan bekerja adalah ketersediaan lapangan kerja untuk menampung angkatan kerja. Kesempatan kerja adalah indikator penting suatu perekonomian. Kesempatan kerja yang luas menurunkan jumlah orang menganggur, meningkatkan produktivitas penduduk dan meningkatkan produksi serta pendapatan nasional. Kesempatan kerja atau permintaan tenaga kerja merupakan permintaan turunan (derived demand) dari permintaan terhadap produk barang dan jasa (Situmorang, 2005).

Pentingnya kesempatan kerja dinyatakan dengan baik oleh Kristianto dalam Tjiptoherijanto, dkk (2008) dengan lima hal. Pertama, penciptaan lapangan kerja serta pembayaran upahnya mungkin merupakan satu-satunya mekanisme yang dapat membagi kembali pendapatan kepada mereka yang sebelumnya tanpa pekerjaan. Kedua, pengangguran (unemployment) adalah demoralizing, seseorang yang tanpa pekerjaan dapat hilang harga dirinya. Ketiga, pada hakekatnya bekerja adalah baik, apapun dampaknya pada semangat (morale), harga diri atau perasaan lainnya. Keempat, akan muncul keresahan sosial-politik jika sejumlah besar penduduk tidak memperoleh pekerjaan. Kelima, setiap tahun akan muncul sejumlah besar pencari kerja baru.

Hardono dan Handewi (2006) menyatakan bahwa secara umum pendapatan rumah tangga penduduk di Indonesia sudah berdiversifikasi. Derajat kepentingan berdiversifikasi cenderung lebih tinggi pada rumah tangga di wilayah desa yang berpendapatan rendah dan kepala keluarganya memiliki pekerjaan utama sebagai petani.

Adanya kegiatan pemberdayaan masyarakat melalui serangkaian program pemulihan mangrove di Desa Rugemuk, diperkirakan akan berdampak pada pemulihan ekologis dan ekonomis mangrove serta meningkatnya peluang bekerja/berusaha atau meningkatnya keanekaragaman sumber mata pencaharian di wilayah Desa Rugemuk. Adanya peningkatan peluang bekerja/berusaha atau peningkatan keanekaragaman sumber mata pencaharian diperkirakan akan berdampak pada peningkatan pendapatan rumah tangga masyarakat pesisir di Desa Rugemuk.

\section{Pendapatan Keluarga}

Menurut Sukirno (2006) pendapatan adalah jumlah penghasilan yang diterima oleh penduduk atas prestasi kerjanya selama satu periode tertentu, baik harian, mingguan, bulanan ataupun tahunan. Rusaknya hutan mangrove berdampak negatif bagi rumah tangga nelayan, karena pendapatan mereka menurun sebelum hutan mangrove direhabilitasi. Sebaliknya, setelah direhabilitasi pendapatan rumah tangga masyarakat nelayan cukup memadai untuk memenuhi kebutuhan hidupnya (Roswita, 2016).

Hardono dan Handewi (2006) menyatakan bahwa secara umum pendapatan rumah tangga penduduk di Indonesia sudah berdiversifikasi. Derajat kepentingan berdiversifikasi cenderung lebih tinggi pada rumah tangga di wilayah desa yang berpendapatan rendah dan kepala keluarganya memiliki pekerjaan utama sebagai petani.

\section{METODE PENELITIAN}

Penelitian ini dilaksanakan pada bulan Mei-Juni 2018 di Desa Rugemuk Kecamatan Pantai Labu, Kabupaten Deli Serdang Provinsi Sumatera Utara dipilih secara purposive sampling karena merupakan lokasi sasaran program pemulihan mangrove yang digulirkan oleh Perguruan Tinggi (USU, UMSU, Universitas Negeri Medan) bersama Pemerintah Daerah, LSM serta badan usaha swasta berbasis partisipasi masyarakat dari awal tahun 2013 sampai akhir tahun 2016 (awal 2017). Sebelum pelaksanaan program tersebut, Desa Rugemuk merupakan desa di wilayah pesisir Kabupaten Deli Serdang dengan kondisi kerusakan hutan mangrove yang relatif paling parah. Alat dan bahan yang digunakan pada penelitian ini yaitu: alat tulis, GPS, software Micrososft Office, SPSS, software arcGIS 10.2.

Kegiatan yang dilakukan meliputi pengambilan data primer dan pengumpulan data sekunder. Pengambilan data primer yang mencakup inventarisasi vegetasi mangrove, data luas hutan mangrove sebelum dan sesudah program pemulihan, ketersediaan bahan baku agroindustri sebelum dan sesudah program pemulihan, kemudahan bekerja/berusaha sebelum dan sesudah program pemulihan, pendapatan rumah tangga sebelum dan 
sesudah program pemulihan. Pengumpulan data sekunder mencakup pengumpulan peta, data demografi dan data penelitian sebelumnya.

Metode yang digunakan untuk penentuan besar/jumlah sampel dalam penelitian ini ditentukan dengan menggunakan metode Slovin dengan persamaan sebagai berikut:

$$
n=\frac{\mathrm{N}}{1+\mathrm{Ne}^{2}}
$$

Dimana:

$\mathrm{n}$ : Besar sampel

$\mathrm{N}$ : Jumlah populasi

e : Batas toleransi kesalahan (error tolerance)

Dengan $\mathrm{N}=381 \mathrm{KK}$ dan nilai $\mathrm{e}=0,1$ maka diperoleh jumlah sampel $(n)=79$ sampel.

Metode pengambilan sampel yang digunakan adalah dengan metode simple random sampling atau pengambilan sampel dilakukan atau dipilih satu per satu secara acak (semua mendapatkan kesempatan yang sama untuk dipilih) dan jika sudah dipilih, tidak dapat dipilih lagi. Populasi dalam penelitian ini adalah masyarakat pesisir yang kehidupannya berhubungan dengan keberadaan hutan mangrove di Desa Rugemuk, Kecamatan Pantai Labu, Kabupaten Deli Serdang. Populasi yang dimaksud dalam penelitian ini adalah masyarakat pesisir Dusun 3 dan Dusun 4, Desa Rugemuk yang menjadi sasaran program pemulihan pesisir yang pada tahun 2017 berjumlah $381 \mathrm{KK}$.

Untuk mempermudah proses pengukurannya maka variabel-variabel dalam penelitian ini dioperasionalisasikan seperti tersaji pada Tabel 1.

Tabel 1. Operasionalisasi Variabel Penelitian

\begin{tabular}{|c|c|c|c|}
\hline No & Variabel & Indikator & $\begin{array}{c}\text { Skala } \\
\text { Pengukuran }\end{array}$ \\
\hline 1. & $\begin{array}{l}\text { Luas Hutan } \\
\text { Mangrove }\end{array}$ & $\begin{array}{l}\text { Luas hutan } \\
\text { mangrove di Desa } \\
\text { Rugemuk berbasis } \\
\text { Citra Satelit } \\
\text { Landsat pada tahun } \\
2013 \text { dan } 2017\end{array}$ & Rasio \\
\hline 2. & $\begin{array}{l}\text { Ketersediaan } \\
\text { bahan baku } \\
\text { agroindustri } \\
\text { pesisir }\end{array}$ & $\begin{array}{l}\text { Persepsi } \\
\text { Responden } \\
\text { terhadap } \\
\text { Peningkatan/ } \\
\text { Penurunan } \\
\text { Ketersediaan } \\
\text { bahan baku } \\
\text { Industri Belacan } \\
\text { dan Udang Kering }\end{array}$ & Kualitatif \\
\hline 3. & $\begin{array}{l}\text { Kesempatan } \\
\text { Kerja dan } \\
\text { Berusaha }\end{array}$ & $\begin{array}{l}\text { Persepsi } \\
\text { Responden } \\
\text { Terhadap } \\
\text { Peningkatan/ } \\
\text { Penurunan } \\
\text { kesempatan } \\
\text { kerja/berusaha }\end{array}$ & Kualitatif \\
\hline 4. & $\begin{array}{l}\text { Pendapatan } \\
\text { Rumah }\end{array}$ & $\begin{array}{l}\text { Pendapatan } \\
\text { Keluarga (Onfarm }\end{array}$ & Rasio \\
\hline
\end{tabular}

\begin{tabular}{|l|l|l|l|}
\hline & $\begin{array}{l}\text { Tangga } \\
\text { Pesisir }\end{array}$ & dan Off-farm) & \\
\hline
\end{tabular}

Metode analisis data yang digunakan untuk menguji hipotesis tentang dampak program pemulihan hutan mangrove terhadap luasan tutupan hutan mangrove adalah Metode Komparatif-Citra Satelit Landsat-7 ETM+. Komparasi dilakukan dengan membandingkan peta tahun peliputan 2012 yang mewakili kondisi sebelum program pemulihan dilaksanakan secara komprehensif dan tahun 2017 yang mewakili kondisi setelah program pemulihan mangrove dilaksanakan secara komprehensif.

Metode analisis data yang digunakan untuk menguji hipotesis tentang dampak program pemulihan hutan mangrove terhadap ketersediaan bahan baku pada agroindustri pesisir dan dampak program pemulihan hutan mangrove terhadap kesempatan kerja adalah Metode Wilcoxon Match Pairs Test (untuk sampel berukuran besar dengan sebaran normal baku) menggunakan formula sebagai berikut:

$$
T^{*}=\frac{T-\frac{n(n+1)}{4}}{\sqrt{\frac{n(n+1)(2 n+1)}{24}}}
$$

Statistik uji yang digunakan untuk masing-masing hipotesis adalah :

a) Hipotesis a: $T=T^{\prime}=\min (T-, T+)$

b) Hipotesis b: $T=T$

c) Hipotesis c: $T=T+$

Kaidah Keputusan

a) Hipotesis a: Tolak $H_{0}$ jika $T^{\prime} \leq \operatorname{Tn}(\alpha / 2)$

b) Hipotesis b: Tolak $H_{0}$ jika $T$ - $\leq \operatorname{Tn}(\alpha)$

Hipotesis c: Tolak $H_{0}$

Metode analisis data yang digunakan untuk menguji hipotesis tentang dampak program pemulihan hutan mangrove terhadap pendapatan rumah tangga pesisir adalah Paired Sample Test yang sampelnya adalah sampel besar sehingga menggunakan $U j i-Z$ dengan formula:

$$
z=\frac{\left|\bar{x}_{1}-\bar{x}_{2}\right|}{\sqrt{\left(\sigma_{1}^{2} / n_{1}\right)+\left(\sigma_{2}^{2} / n_{2}\right)}}
$$

Kriteria pengujian:

Untuk $\quad \mathrm{H}_{0}: \mu_{1}=\mu_{2}$ dan $\mathrm{H}_{1}: \mu_{1}<\mu_{2}$

a) $\mathrm{H}_{0}$ diterima jika $\mathrm{Z}_{0} \geq-\mathrm{Z}_{\alpha}$

b) $\mathrm{H}_{0}$ ditolak jika $\mathrm{Z}_{0}<-\mathrm{Z}_{\alpha}$

Kaidah keputusan:

Jika $\mathrm{H}_{0}$ diterima maka $\mathrm{H}_{1}$ ditolak

Jika $\mathrm{H}_{0}$ ditolak maka $\mathrm{H}_{1}$ diterima

HASIL DAN PEMBAHASAN

Karakteristik Sampel 
Sampel penelitian adalah bagian dari masyarakat nelayan Desa Rugemuk (Dusun 3 dan Dusun 4) yang menjadi sasaran program pemulihan. Mereka pada umumnya adalah nelayan Desa Rugemuk yang saat dini hari pergi melaut dan pulang sore hari dengan membawa hasil laut. Karakteristik sampel yang dipaparkan dalam hal ini meliputi umur, pendidikan, lama pengalaman melaut, jenis usaha sambilan dan jumlah tanggungan. Karakteristik sampel nelayan di Desa Rugemuk dapat dilihat pada Tabel 2.

Tabel 2 menunjukkan bahwa sebanyak 26 sampel nelayan atau dengan persentase 32,91\% memiliki rentang umur 30-39 tahun. Artinya sampel pada umumnya masih dalam kategori usia produktif sehingga dari segi fisik diperkirakan masih mampu bekerja atau mengerjakan usaha dengan baik.

Tabel tersebut juga menampilkan sebanyak 47 sampel atau sekitar 59,50\% adalah nelayan Desa Rugemuk yang berada pada interval (rentang) pendidikan antara 0-6 tahun atau pendidikan terakhir nelayan hanya pada jenjang SD (sekolah dasar). Ini menunjukkan bahwa level pendidikan responden termasuk kategori rendah. Hal ini belum sesuai target pemerintah yang mengharuskan warganya mengecap pendidikan selama 12 tahun.

Tabel 2. Karakteristik Sampel di Desa Rugemuk

\begin{tabular}{|c|c|c|c|}
\hline Uraian & Interval & $\begin{array}{c}\text { Jumlah } \\
\text { (sampel) }\end{array}$ & $\begin{array}{c}\text { Persentase } \\
(\%)\end{array}$ \\
\hline \multirow{6}{*}{$\begin{array}{l}\text { 1. Umur } \\
\text { (tahun) }\end{array}$} & \multirow{5}{*}{$\begin{array}{l}20-29 \\
30-39 \\
40-49 \\
50-59 \\
60-69\end{array}$} & 9 & 11,40 \\
\hline & & 26 & 32,91 \\
\hline & & 24 & 30,37 \\
\hline & & 9 & 11,40 \\
\hline & & 11 & 13,92 \\
\hline & Total & 79 & 100 \\
\hline \multirow{5}{*}{$\begin{array}{l}\text { 2. Pendidikan } \\
\text { (tahun) }\end{array}$} & \multirow{4}{*}{$\begin{array}{c}0-6 \\
7-9 \\
10-12 \\
>12\end{array}$} & 47 & 59,50 \\
\hline & & 17 & 21,52 \\
\hline & & 14 & 17,72 \\
\hline & & 1 & 1,26 \\
\hline & Total & 79 & 100 \\
\hline \multirow{6}{*}{$\begin{array}{l}\text { 3. Lama } \\
\text { pengalam- } \\
\text { an melaut/ } \\
\text { sebagai } \\
\text { nelayan } \\
\text { (tahun) }\end{array}$} & \multirow{5}{*}{$\begin{array}{c}0-9 \\
10-19 \\
20-29 \\
30-39 \\
>40\end{array}$} & 20 & 25,32 \\
\hline & & 21 & 26,58 \\
\hline & & 17 & 21,52 \\
\hline & & 12 & 15,18 \\
\hline & & 9 & 11,40 \\
\hline & Total & 79 & 100 \\
\hline \multirow{4}{*}{$\begin{array}{l}\text { 4. Jumlah } \\
\text { Tanggung- } \\
\text { an (orang) }\end{array}$} & \multirow{3}{*}{$\begin{array}{l}1-2 \\
3-4 \\
5-6\end{array}$} & 26 & 32,91 \\
\hline & & 39 & 49,37 \\
\hline & & 14 & 17,72 \\
\hline & Total & 79 & 100 \\
\hline
\end{tabular}

Dari Tabel 2 dapat terlihat bahwa sebanyak 21 sampel atau $26,58 \%$ memiliki lama pengalaman melaut dengan rentang antara 10-19 tahun, hal ini menunjukkan bahwa mereka telah relatif lama bekerja sebagai nelayan.
Selain itu dari Tabel dapat dilihat juga bahwa sebanyak 39 sampel atau 49,37\% menyatakan bahwa setiap kepala rumah tangga nelayan di Desa Rugemuk memiliki jumlah tanggungan keluarga sebanyak 3-4 orang. Kepala keluarga umumnya menanggung istri, anak dan sanak saudara yang tinggal di dalam satu rumah.

\section{Luas Hutan Mangrove}

Luas hutan mangrove hasil analisis dengan menggunakan metode deskriptif dibantu dengan interpretasi peta kawasan (terutama peta penggunaan lahan) yang bersumber dari peta Citra Satelit Landsat-7 ETM+ dengan tahun peliputan yaitu tahun 2012 (sebelum program pemulihan mangrove dilaksanakan) adalah 9 ha, sedangkan pada tahun peliputan 2017 (setelah program pemulihan mangrove dilaksanakan di Desa Rugemuk) adalah 23,5 ha (Gambar 1). Ini menunjukkan bahwa dalam rentang waktu sekitar 5 tahunan, luas hutan mangrove mengalami peningkatan lebih dari dua kali lipat.

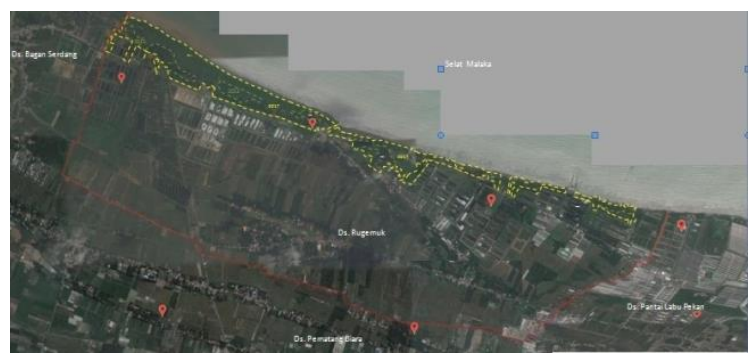

Gambar 1. Peta Luas Hutan Mangrove Setelah Program Pemulihan

\section{Hasil Pengujian Hipotesis \\ Ketersediaan Bahan Baku Agroindustri}

Program pemulihan hutan mangrove menimbulkan dampak yaitu meningkatnya ketersediaan bahan baku agroindustri pesisir (udang) dengan dominasi skor 3 (cukup melimpah) menurut persepsi 56,97 persen responden. Bila dibandingkan dengan sebelum pemulihan hutan mangrove ketersediaan bahan baku untuk agroindustri pesisir untuk pembuatan terasi dan udang kering hanya memiliki skor 1 (tidak tersedia) menurut persepsi 49,36 persen responden dan skor 2 (sedikit tersedia) menurut persepsi 43,04 persen responden, seperti disajikan pada Tabel 3.

Tabel 3. Tanggapan Responden tentang Ketersediaan Bahan Baku Agroindustri Pesisir

\begin{tabular}{|c|c|c|c|}
\hline \multirow{2}{*}{ No. } & \multicolumn{3}{|c|}{ Sebelum Program Pemulihan Mangrove } \\
\cline { 2 - 4 } & $\begin{array}{c}\text { Kategori } \\
\text { Ketersediaan }\end{array}$ & $\begin{array}{c}\text { Jumlah } \\
\text { Sampel }\end{array}$ & $\%$ \\
\hline 1. & Tidak tersedia & 39 & 49,36 \\
\hline 2. & Sedikit tersedia & 34 & 43,04 \\
\hline 3. & $\begin{array}{c}\text { Cukup melimpah } \\
\text { tersedia }\end{array}$ & 6 & 7,60 \\
\hline 4. & Melimpah tersedia & 0 & 0 \\
\hline 5. & Sangat melimpah & 0 & 0 \\
\hline
\end{tabular}




\begin{tabular}{|c|c|c|c|}
\hline & tersedia & $\mathbf{7 9}$ & $\mathbf{1 0 0}$ \\
\hline \multicolumn{3}{|c|}{ Total } & \multicolumn{3}{|c|}{ Sesudah Program Pemulihan Mangrove } \\
\hline \multirow{2}{*}{ No. } & $\begin{array}{c}\text { Kategori } \\
\text { Ketersediaan }\end{array}$ & $\begin{array}{c}\text { Jumlah } \\
\text { Sampel }\end{array}$ & \% \\
\cline { 2 - 4 } & Tidak tersedia & 7 & 8,86 \\
\hline 1. & Sedikit tersedia & 14 & 17,72 \\
\hline 2. & $\begin{array}{c}\text { Cukup melimpah } \\
\text { tersedia }\end{array}$ & 45 & 56,97 \\
\hline 3. & Melimpah tersedia & 12 & 15,18 \\
\hline 4. & $\begin{array}{c}\text { Sangat melimpah } \\
\text { tersedia }\end{array}$ & 1 & 1,27 \\
\hline 5. & Total & $\mathbf{7 9}$ & $\mathbf{1 0 0}$ \\
\hline
\end{tabular}

Sumber : Diolah dari Data Primer, 2018

Berdasarkan Tabel 3 tersebut terlihat bahwa menurut responden, terjadi peningkatan ketersediaan bahan baku agroindustri pesisir setelah program pemulihan hutan mangrove.

\section{Tabel 4. Uji Wilcoxon}

\begin{tabular}{|c|c|c|c|}
\hline \multirow{2}{*}{ No. } & \multicolumn{3}{|c|}{ Sebelum Program Pemulihan Mangrove } \\
\hline & $\begin{array}{c}\text { Kategori } \\
\text { Ketersediaan }\end{array}$ & $\begin{array}{l}\text { Jumlah } \\
\text { Sampel } \\
\end{array}$ & $\%$ \\
\hline 1. & $\begin{array}{l}\text { Tidak tersedia atau } \\
\text { sangat terbatas }\end{array}$ & 15 & 18,98 \\
\hline 2. & Sedikit atau terbatas & 47 & 59,50 \\
\hline 3. & Cukup banyak & 17 & 21,52 \\
\hline 4. & Banyak & 0 & 0 \\
\hline 5. & Sangat banyak & 0 & 0 \\
\hline \multicolumn{2}{|r|}{ Total } & 79 & 100 \\
\hline \multirow{2}{*}{ No. } & \multicolumn{3}{|c|}{ Sesudah Program Pemulihan Mangrove } \\
\hline & $\begin{array}{c}\text { Kategori } \\
\text { Ketersediaan }\end{array}$ & $\begin{array}{l}\text { Jumlah } \\
\text { Sampel } \\
\end{array}$ & $\%$ \\
\hline 1. & $\begin{array}{l}\text { Tidak tersedia atau } \\
\text { sangat terbatas }\end{array}$ & 0 & 0 \\
\hline 2. & Sedikit atau terbatas & 7 & 8,86 \\
\hline 3. & Cukup banyak & 35 & 44,30 \\
\hline 4. & Banyak & 30 & 37,97 \\
\hline 5. & Sangat banyak & 7 & 8,87 \\
\hline & Total & 79 & 100 \\
\hline
\end{tabular}

Tabel 4. menunjukkan bahwa berdasarkan uji Wilcoxon, hasil $Z_{\text {hitung }}$ adalah sebesar 6,904, sedangkan $Z_{\text {tabel }}$ dengan probabilitas $(\alpha / 2)=2,5 \%$ adalah sebesar 1,96. Selanjutnya karena $Z_{\text {hitung }}$ $(6,904)>Z_{\text {tabel }}(1,96)$, maka dapat diambil kesimpulan bahwa Hipotesis $\mathrm{H}_{1}$ yang menyatakan ada peningkatan ketersediaan bahan baku agroindustri pesisir sebagai dampak bergulirnya program pemulihan hutan mangrove diterima. Kemudian hipotesis $\mathrm{H}_{\mathrm{o}}$ yang menyatakan tidak ada dampak ketersediaan bahan baku agroindustri terhadap program pemulihan hutan mangrove ditolak.
Tabel 5. Hasil Uji Wilcoxon Signed-Rank Dampak Terhadap Ketersediaan Bahan Baku Agroindustri

\begin{tabular}{|l|r|}
\hline \multicolumn{2}{|c|}{ Text Statistics } \\
\hline \multicolumn{2}{|c|}{ Ketersediaan Bahan Baku Sesudah-Ketersediaan Bahan } \\
Baku Sebelum
\end{tabular}

Hasil uji beda dapat menunjukkan bahwa ketersediaan bahan baku agroindustri (dalam hal ini yang dimaksud adalah udang) sesudah program pemulihan hutan mangrove berbeda atau mengalami peningkatan signifikan dibanding sebelum program pemulihan. Hal ini sesuai dengan hasil kajian Paw dan Chua (1989) yang melakukan penelitian di Filipina dan mendapatkan adanya hubungan antara ekosistem mangrove dengan sumberdaya ikan atau hubungan positif antara area dan kualitas mangrove dan hasil penangkapan udang penaeid.

\section{Kesempatan Bekerja/Berusaha}

Variasi jenis kesempatan kerja yang terdapat di Desa Rugemuk yaitu mencari/memancing kepiting mangrove, mencari/memancing udang mangrove, nelayan/melaut, mengolah udang/kepiting (belacan/ udang kering), mengolah makanan dari bahan mangrove, usaha penangkaran mangrove, beternak dan berjualan/kedai sampah.

Tabel 5 menunjukkan bahwa program pemulihan hutan mangrove menimbulkan dampak terhadap kesempatan bekerja yaitu terjadi peningkatan dari sebelum program pemulihan dengan skor 2 (sedikit atau terbatas) menurut persepsi 47 sampel atau 59,50 persen responden. Sedangkan, sesudah program pemulihan hutan mangrove meningkat menjadi skor 3 dan 4 (cukup banyak dan banyak) masing-masing menurut persepsi 35 sampel dan 30 sampel responden atau masing-masing 44,30 persen dan 37,97 persen dari total sampel, seperti terlihat pada Tabel 5. Hasil penelitian menunjukkan bahwa menurut responden telah terjadi peningkatan kesempatan bekerja dan berusaha di wilayah pesisir setelah program pemulihan hutan mangrove bergulir.

Hasil penelitian ini senada bila dibandingkan dengan penelitian mengenai dampak kerusakan ekosistem mangrove di Kecamatan Secanggang oleh Rosni (2009) yang menyatakan bahwa setelah terjadinya kerusakan mangrove sekitar $40 \%$ masyarakat pantai menyatakan sulit bekerja/berusaha dan hanya $2,7 \%$ yang menyatakan bekerja dan berusaha di sektor perikanan sesudah kerusakan ekosistem mangrove. Menurut Penelitian Purwoko (2008), kerusakan ekosistem hutan bakau/mangrove berdampak terhadap kesempatan kerja dan berusaha, dimana $85,4 \%$ masyarakat berpendapat bahwa sebelum kerusakan mereka agak mudah sampai dengan mudah mendapatkan kesempatan kerja dan 
berusaha, namun setelah terjadinya kerusakan terjadi sebaliknya dimana $85,4 \%$ responden menyatakan agak sulit sampai dengan sulit mendapatkan kesempatan bekerja dan berusaha.

Tabel 6. menunjukkan bahwa berdasarkan uji Wilcoxon, hasil $Z_{\text {hitung }}$ adalah sebesar 7,448 , sedangkan $Z_{\text {tabel }}$ dengan probabilitas $(\alpha / 2)=2,5 \%$ adalah sebesar 1,96 . Selanjutnya karena nilai $Z_{\text {hitung }}$ $(7,448)>Z_{\text {tabel }}(1,96)$, maka dapat diambil kesimpulan bahwa Hipotesis $\mathrm{H}_{1}$ yang menyatakan ada peningkatan jumlah kesempatan bekerja dampak program pemulihan hutan mangrove diterima. Kemudian Hipotesis $\mathrm{H}_{\mathrm{o}}$ yang menyatakan tidak ada penambahan kesempatan bekerja dampak program pemulihan hutan mangrove ditolak.

Tabel 6. Hasil Uji Wilcoxon Signed-Rank Dampak terhadap Kesempatan Bekerja

\begin{tabular}{|l|l|}
\hline \multicolumn{2}{|c|}{ Text Statistics } \\
\hline \multicolumn{2}{|c|}{ Ketersediaan Bekerja Sesudah-Kesempatan Bekerja } \\
Sebelum
\end{tabular}

Hasil uji beda dapat menunjukkan bahwa kesempatan bekerja/berusaha sesudah program pemulihan hutan mangrove berbeda nyata atau mengalami peningkatan signifikan dibanding sebelum program pemulihan. Hal ini sesuai dengan hasil penelitian Rosni (2009) dan Purwoko (2008) yang menyatakan bahwa terdapat perbedaan yang signifikan antara kesempatan bekerja/berusaha sebelum dengan sesudah terjadinya kerusakan ekosistem mangrove. Dengan kondisi hutan mangrove yang rusak maka kesempatan bekerja dan berusaha makin menurun, sebaliknya dengan kondisi hutan mangrove pulih maka kesempatan bekerja dan berusaha juga pulih atau makin meningkat.

\section{Pendapatan Rumah Tangga Pesisir}

Program pemulihan hutan mangrove menimbulkan dampak yaitu meningkatnya pendapatan rumah tangga pesisir. Pada tabel berikut disajikan data perubahan pendapatan rumah tangga nelayan sebelum dan sesudah program pemulihan mangrove, seperti disajikan pada Tabel 7 .

Tabel 7. Pendapatan Rumah Tangga Nelayan per Bulan Sebelum dan Sesudah Program Pemulihan Mangrove

\begin{tabular}{|c|c|c|}
\hline Pendapatan & $\begin{array}{c}\text { Sebelum } \\
\text { (Rp/bulan) }\end{array}$ & $\begin{array}{c}\text { Sesudah } \\
\text { (Rp/bulan) }\end{array}$ \\
\hline Total & 103.850 .000 & 128.026 .922 \\
Rata-rata & 1.314 .557 & 1.620 .594 \\
\hline
\end{tabular}

Dari Tabel 7. dapat dilihat rata-rata pendapatan rumah tangga pesisir per bulan sebelum program pemulihan mangrove adalah sebesar Rp 1.314.557, sedangkan sesudah program pemulihan mangrove dengan mempertimbangkan tingkat inflasi adalah sebesar Rp 1.620.594. Artinya pendapatan rumah tangga nelayan per bulan sesudah program pemulihan mangrove mengalami peningkatan dibanding sebelum program pemulihan mangrove. Peningkatan tersebut terjadi karena adanya peningkatan produktivitas kawasan hutan mangrove dan peningkatan kesempatan kerja.

Namun, untuk melihat signifikansi perbedaan pendapatan rumah tangga nelayan per bulan sebelum dan sesudah program pemulihan mangrove, maka dilakukan uji paired sampel, sebagai berikut :

Tabel 8. Hasil Uji Beda Rata-rata T-Test Pendapatan Rumah Tangga Masyarakat Pesisir Sebelum dan Sesudah Dampak Pemulihan

\begin{tabular}{|c|c|c|c|c|c|c|c|c|}
\hline & \multicolumn{4}{|c|}{ Paired Differences } & \multirow[t]{2}{*}{$\mathbf{t}$} & \multirow[t]{2}{*}{ df } & \multirow{2}{*}{ Sig. (2-tailed) } \\
\hline & & Mean & $\begin{array}{l}\text { Std. } \\
\text { Deviation }\end{array}$ & $\begin{array}{l}\text { Std. } \\
\text { Error } \\
\text { Mean }\end{array}$ & $\begin{array}{l}95 \% \\
\text { Confidence } \\
\text { Interval of } \\
\text { the } \\
\text { Difference }\end{array}$ & & & \\
\hline $\begin{array}{l}\text { Pair 1 } \\
\text { Sesudah } \\
\text { Pendapatan } \\
\text { Program }\end{array}$ & $\begin{array}{r}\text { Pendapatan } \\
\text { Program } \\
\text { Sebelum }\end{array}$ & $\begin{array}{l}306036.99 \\
024\end{array}$ & $\begin{array}{l}416721.71 \\
420\end{array}$ & $\begin{array}{l}46884.855 \\
87\end{array}$ & 212696.41236 & 6.527 & 78 & .000 \\
\hline
\end{tabular}

\section{KESIMPULAN}

Beberapa kesimpulan yang dapat ditarik dari hasil penelitian ini adalah:

1. Program pemulihan hutan mangrove berdampak signifikan meningkatkan luas hutan mangrove di Desa Rugemuk
2. Program pemulihan hutan mangrove berdampak signifikan meningkatkan ketersediaan bahan baku agroindustri pesisir di Desa Rugemuk

3. Program pemulihan hutan mangrove berdampak signifikan meningkatkan kesempatan bekerja/ berusaha di Desa Rugemuk

4. Program pemulihan hutan mangrove berdampak signifikan meningkatkan pendapatan rumah tangga di Desa Rugemuk 


\section{DAFTAR PUSTAKA}

Auliyani, Diah., Boedi, H dan Kismartini. 2013. Pengaruh Rehabilitasi Mangrove Terhadap Kondisi Sosial Ekonomi Masyarakat Pesisir Kabupaten Rembang. ISBN 978-60217001-1-2 317. Universitas Diponegoro. Semarang.

Gasperz V. 1990. Analisis Sistem Terapan. Tarsito. Bandung.

Ichsan. 2017. Pengembangan Agroindustri Di Aceh. Sefa Bumi Persada. Lhokseumawe.

International Association for Impact Assessment. 2003. Social Impact Assessment International Principles. IAIA Special Publications Series No.2. Fargo, US

KBBI. 2010. Kamus Besar Bahasa Indonesia Online. Diakses tanggal 15 Februari 2018. [Pukul 18.50 Wib].

Kabupaten Deli Serdang dalam Angka. 2013. BPS Kabupaten Deli Serdang.

Kecamatan Pantai Labu dalam Angka. 2017. BPS. Kabupaten Deli Serdang.

Murdiyanto, B. 2003. Mengenal, Memelihara, dan Melestarikan Ekosistem Bakau. Direktorat Jenderal Perikanan Tangkap Departemen Kelautan dan Perikanan. Jakarta.

Novianty, R. Sukaya, S dan Donny, J. 2004. Identifikasi Kerusakan dan Upaya Rehabilitasi Ekosistem Mangrove di Pantai Utara Kabupaten Subang. Universitas Padjajaran. Bandung.

Purwoko, A. 2008. Dampak Kerusakan Ekosistem Hutan Bakau (Mangrove) Terhadap Pendapatan Masyarakat di Kecamatan Secanggang, Kabupaten Langkat. USU Press. Medan.

Rosni. 2009. Penurunan Kualitas Ekosistem Mangrove Hubungannya dengan Pendapatan Masyarakat Nelayan di Kecamatan Secanggang, Kabupaten Langkat, Provinsi Sumatera Utara. Jurnal Geografi Vol. 01 Nomor 01/ Agustus 2009.

Roswita Hafni. 2016. Analisis Dampak Rehabilitasi Hutan Mangrove terhadap Pendapatan Masyarakat Desa Lubuk Kertang Kabupaten Langkat. Universitas Muhammadiyah Sumatera Utara. Medan.

Roy, R., Robin dan Lewis. 2007. Restorasi Hutan Bakau Berwawasan Ekologi. Mangrove Action Project- Indonesia Program. Jakarta.

Rukminto, A. I. 2005. Ilmu Kesejahteraan Sosial dan Pekerjaan Sosial: Pengantar pada Pengertian dan Beberapa Pokok Bahasan. FISIP UI Press. Jakarta.

Septyohadi. 2004. Acuan Dasar (Primer) Perhimpunan Ekologi Restorasi Internasional (SER Internasional)
Terhadap Restorasi Ekologis. Universitas Brawijaya. Malang.

Situmorang, Boyke, 2005. Elastisitas Kesempatan Kerja terhadap Pertumbuhan Ekonomi, Upah Minimum dan Suku Bunga di Indonesia Tahun 1990-2003. IPB Press. Bogor. 